\title{
Towards an Extra-Linguistic Critique of J.L. Austin's Speech Act Theory
}

\author{
Acheoah John Emike \\ English Department, Ajayi Crowther University \\ P.M.B. 1066, Oyo, Nigeria \\ Tel: 08039410188 E-mail: Actualemike@gmail.com
}

Received: 12-05-2013

doi:10.7575/aiac.ijalel.v.2n.5p.241
Accepted: 17-07-2013

Published: 01-09-2013

\begin{abstract}
The paper is an extra-linguistic critique of Austin's speech act theory. In the context of the paper, extra-linguistic issues capture those factors that "legitimize" violations from the norms of English which are evident in Austin's theory. We investigate the strengths and weaknesses of the theory from a socio-pragmatic perspective, exploring discursively, the Nigerian existential experience. The critique hinges on three evolved theoretical concepts (Geoimplicature, Emergent Context and Pragmadeviant) in the investigation of the strengths and weaknesses of Austin's speech act theory. The study finds out that despite the strengths of the theory, some postulations therein are bedeviled by the dynamics of human communication. Conclusively, the paper contends for an "illocutionary component" of meaning as opposed to the age-long "propositional component" of meaning.
\end{abstract}

Keywords: Speech Act, Speech Community, Society, Geoimplicature, Emergent Context, Pragmadeviant

\section{Introduction}

We subject Austin's speech act theory to an extra-linguistic critique. We have used the term "extra-linguistic" to capture the socio-pragmatic motivations of language use in regional communication, which invariably presupposes the social, environmental, situational, cultural and diachronic contexts of linguistic elements used "beyond the sentence". The paper is therefore interested in the external properties which language has in communicative events and how such external (extra-linguistic) properties bedevil some of the linguistic-driven postulations in Austin's (1962) speech act theory.

Pragmatics is relevant to various disciplines with a stake on how utterances are understood. Even when there are underlying universals of usage, as seems to be the case in the construction of polite expressions, there is considerable room for cross-cultural misunderstanding ${ }^{1}$. Our review of existing literature on "language and context" reveals that pragmatic or speech act theories have loopholes because such theories do not answer certain questions about contextual dynamics in language-use across socio-cultural backgrounds. Austin's theory strongly upholds "linguistic conventions" for the performance of speech acts. The roles of the norms of various regions of the world tend to be deemphasized. We note that the cultural implications of speech acts and their attendant notions such as implicatures, presuppositions, world knowledge and mutual contextual beliefs, can be viewed from global, national and ethnic classification of speech behaviours.

\section{Theoretical Underpinnings}

In this section, we examine basic issues in Austin's speech act theory. We also review sociolinguistics, speech community and society very briefly towards giving the paper some theoretical base.

\subsection{Austin's Speech Act Theory}

A major feat of Austin's theory is that it generated widespread interest on how words count as actions ${ }^{2}$. Austin makes a distinction between performatives and constatives. Constatives are statements which have been traditionally treated as having the property of being true or false. But performatives may not meet this criterion. They index the fact that an utterance uttered, is the performance of an action. They transcend mere stating. Rather than being true or false, performatives are either felicitous or infelicitous. In Austin's view, performatives and constatives differ in the areas of "doing" and "saying". The felicity conditions for performatives include the following:

(i) Certain conventional procedures must be fulfilled;

(ii) Certain words have to be uttered in certain circumstances;

(iii) All participants of the discourse must execute the procedures correctly and completely;

(iv) The particular persons and circumstances in a given situation must be appropriate for the particular procedure and their thoughts and feelings should also be germane to the situation. 
The violation of the above procedures makes performatives infelicitous. According to Austin, perlocutionary acts are "the effects on, or thoughts or feelings of the audience or the speaker produced by the act of saying something". He distinguishes between "the act of doing x" (or "achieving x") and "the act of attempting to do x". This distinction is vital for speech act theory since whether speakers intend to produce an effect or not, such an effect may occur.

\subsection{Austin's Speech Act Taxonomy}

As a result of Austin's pioneering effort in speech act classification, the study of the conventional conditions for illocutionary acts and the taxonomy of speech acts have constituted the core of speech act theory. Austin uses the term "some general preliminary classification" in the classification of illocutionary acts. He distinguishes five general classes, identified by their illocutionary forces. He does not provide a clear basis for his taxonomy but states that illocutionary forces concern the purpose or function of a particular utterance; whether it attempts to alter the state of things or the world, whether it is seen as an effort to make the hearer do something, or whether the speech act commits the speaker to a particular course of action or involves an exercise of the speaker's authority. He proposes five classes finally: Verdictives, Exercitives, Commissives Behabitives and Expositives.

\subsection{Sociolinguistics}

The term "sociolinguistics" is essentially the study of the relationship that language has with socio-cultural nuances. It elucidates language phenomena within the society in terms of the various functions and informants of language at the different social levels in the society. Edward Sapire (1929) gives insights on the interrelationship between language and social reality. However, we shall not expatiate on his position within the scope of this paper.

\subsection{Society}

People who live together in a community, constitutes "society". The components of society include: nation, speech community, state, race and ethnic group. However, the paper will briefly define speech community below and exclude the other components.

\subsection{Speech Community}

When a single language captures the experiences and behaviour of a community of speakers, we refer to such speakers as a speech community.

\section{Research Methods}

Our corpora are eleven postulations in Austin (Ibid.). We have labeled them as A1-A11. Each label contains the postulation being expressed. Thereafter, we examine the strengths and weaknesses of Austin's speech act theory through an integrative discourse; insights from pragmatics (mutual contextual beliefs, presuppositions) and sociolinguistics (speech community and society) direct the critique.

\section{Presentation of Corpora}

A1: Speech acts can be locutionary (performing an act OF saying something), illocutionary (performing an act IN saying something) and perlocutionary (performing an act BY saying something ) ${ }^{3}$;

A2: Speech acts can either be performatives or constatives, of which performatives can be felicitous or infelicitous, whereas constatives can be true or false;

A3: A locutionary act can be a phonetic act or a rhetic act;

A4: The performer of an act (e.g. christening a ship,) should be in the position to do so;

A5: Participants execute discourse procedures correctly and completely for performatives to be felicitous;

A6: Persons and circumstances in speech situations must be appropriate for the procedures being invoked, if performatives are to be felicitous;

A7: The conduct of the participants should be in line with the procedures (i.e. their thoughts and feelings) for effective communication to take place;

A8: Sincerity condition (whether or not speakers have genuine intentions) is a prerequisite for an act of promise;

A9: Performing a speech act involves "doing x" or "attempting to do $\mathrm{x}^{4}$;

A10: In performing speech acts, there is perlocutionary object, uptake, and perlcutionary sequel;

A11: Performatives and constatives differ in the areas of "doing and saying".

\section{Critique of Austin's Theory}

In this section we critique Austin's speech act theory by discussing the strengths and weaknesses.

\subsection{Strengths of Austin's Theory}

Before Austin's work, How to Do Things with Words, language was viewed as a way of making factual assertions, and the other functions of language, tended to be ignored. The work led philosophers to pay more attention to the nondeclarative uses of language. Austin's speech act theory provides preparatory grounds for the investigation of illocutionary acts. The communicative significance of illocutionary acts is tied to the linguistic environments in which they are used. For example, if there were no concept such as "death", the verb "mourn" would not be communicatively significant. Austin's theory which is a landmark in support of the argument in semantics "that the referents precedes 
the referring expressions" explains that speech acts are performed in accordance with some conventions which essentially make them institutional acts.

In the context of globalization, more institutions are bound to evolve with their unique register. If this be the case, more research and insights on illocutionary acts will evolve. Illocutionary acts are worthy of linguistic and philosophical investigation because even when the proposition of a speaker is recognized in an utterance, it remains impossible to ascertain what the speaker means in uttering the utterance in the given language. Indeed, illocutionary acts are crucial elements in the study of meaning. Thus, Austin provides operational terms for contemporary speech act theorists.

Functional linguistics benefits immensely from Austin's postulations contained in A1-A11. However, formal linguistics (phonetics, phonology, grammar or morphology, semantics and lexis) cannot be isolated from the influence of speech act theory. Austin's theory portrays language-use as a component of human behaviour (participants are aware of conventional expressions in certain institutional settings). The concepts, "speakers' stimuli", "utterance" and "hearers' stimuli" argued by the Behavioural Theory of Meaning are strongly implied in Austin's work. According to Bloomfeild (1933), "the meaning of a linguistic form is the situation in which the speaker utters it, and the response which it calls forth in the hearer" 5 .

The Behavioural Theory of Meaning which Bloomfeild champions, captures Austin's classification of speech acts in A1. Obviously, Austin's theory explains what happens as a result of using language intentionally or unintentionally as a "communicative journey of consequence"; he contends that there is to human communication, perlocutionary act which concerns "uptake", "perlocutionary object", "sequel" and "response". These ingredients are typical in every discourse. When participants converge for a communicative event, they already know the business of the moment; for example, advocates know that when they are in courtroom proceedings, language is strictly formal and their illocutionary goals revolve around persuasive discourse towards winning a case for their clients. They also know the ethics which they themselves and the Judge are expected to obey at the context of speech and situation, as appropriate participants for the discourse or domain ${ }^{6}$. The absence of appropriate participants in discourse inhibits mutual knowledge. An indirect speech act to certain participants in a certain speech domain may be a literal proposition to other participants in another speech domain. If the utterance, "My wife could not go to church because she was strong" is uttered by a Christian brother to his Pastor or to a fellow Christian brother, the decoder interprets it as a literal proposition, since Christian dispositions are informed by the doctrine of faith; the weak are expected to say they are strong, and this is essentially part of the shared knowledge (which believers/Christians are expected to have) ${ }^{7}$. The encoder may also use the utterance whether his interlocutor is a Christian or not since the people in the speech community have common knowledge of the implicature in the utterance. This can be viewed as "the pragmatics of speaking".

Besides linguistic elements, non-verbal elements used in discourse are participants-dependent. For example, when a man sees another man and salutes him at attention position, those who witness the action may infer that the receiver of the salutation is superior to the giver, and that both men are officers of any of the armed forces. The above inferences may not hold if the subordinate gives just a handshake to his superior. Indeed, Austin's position explains the role of participant-factor in the inferential process of communication. In the same vein, we do not expect an order given by a young boy to an elderly man to imply "rudeness" if the utterance is uttered in a dramatic performance (drama as a literary genre) in which the encoder and decoder know the relationship that they have with the utterance (a relationship tied to the script, of which the boy is a superior to the elderly man). The contributions of participants of discourse are determined by their knowledge or consciousness of how their status or position relate to the speech event. Despite the fact that a group of students may be of same class, they accept certain remarks from their Head-prefect being a "firstamong-equals". In encoding a directive, the Head-prefect himself knows he is in the appropriate position to do so. He however, knows his utterances have limits. He cannot for example, utter an utterance which only the Principal of the college is in the position to utter. Our argument is therefore that Austin's suggestion of "appropriate participants" in discourse for certain acts to be felicitous, is quite illuminating. However, we understand that he emphasized participantfactor as it applies to formal speech situations, or better still, places where social (institutional) acts are performed. We note that the best places to capture the dynamics or nature of human communication may not just be in formal settings (officialdom). This paper therefore proposes a speech act theory that is multiple-setting based, as this can aid the already urgent task of classifying illocutionary acts appropriately. A linguistic-based use of illocutionary act is problematic to the non-native speaker of English who may not know appropriate ways of selecting illocutionary verbs to reflect the different degrees of politeness in the expression of certain communicative functions of the English sentence, for example, the expression of requests ${ }^{8}$.

\subsection{Weaknesses of Austin's Theory}

Linguistic meaning tends to capture some theses that are erroneously used to argue "that language is basically an instrument for communication, and that the communicative functions of language are the basis for understanding its functions and meanings". Below are the theses:

(a) Communication is the only function, or the only essential function of language;

(b) Other functions of language are derived (in the history of the race or of the individual) from the communicative function;

(c) Every language is actually used in communication.

We note that (a) and (c) reflect more of Austin's speech act theory as they give credit to the use of language according to certain linguistic conventions, whether the speakers direct illocutionary acts are directed at institutional or 
interpersonal communicative goals. Indeed, (b) is a justification of our argument for a cross-cultural study of speech acts which Austin's speech act theory lacks. The derivative function of language is super-ordinate since interpersonal functions of language which this study holds as the core of communication, are encapsulated in the interpersonal function. The practice of classifying language functions is often treated with unhealthy duplication. At the underlying level, language, whether used in interpersonal or institutional communication, (we have chosen these two basic dichotomies in the discussion of language function because other functions are subsumed in them), is used to communicate ideologies or desires. However, the various communication theories tend to explain the institutional functions of language. The term "Geoimplicature" (Cf. Acheoah 2011, Unpublished PhD Disertation, Ahmadu Bello University, Zaria) captures the interpersonal function of language built around the "everydayness" of users of the language in any given geographical region. Our thesis is that the institutional function of language which Austin elucidates is discriminatory and restricted; the rubrics in communication theories are not in line with the norms and linguistic behaviour of a vast percentage of the people in certain regions. Speech behaviour or norms of a particular geographical region transcend communication theories which are known for lack of universality. So long as man continues to change alongside society, communication theories will remain bereaved of applicability and dynamics in the use of natural language. In other words, communication theories fail to adequately accommodate the view "that 'communication' is trying to make your listeners capture the idea in your mind" .

The fact that (b) hinges on the psyches of participants of discourse, aligns with the concept, "Geoimplicature". In native speaking English nations, there are dialectal differences. We opine that this is inimical to universality in the categorization of illocutionary verbs. A cross-cultural approach rather than a linguistic approach to speech act theory will help the situation. Austin himself acknowledges "that the meaning of one's linguistic vehicle cannot be relied on to determine the illocutionary force of one's utterance". He took this position to demonstrate that illocutionary force transcends meaning when meaning is viewed as "sense and reference". This position negates in some instances, his discussion of the performance of illocutionary acts according to some linguistic conventions. We contend that Austin's theory does not elucidate the derivation of meaning via "linguistic patterning" and "linguistic choices". We do not completely ignore a linguistic study of speech act; speakers use mastery of linguistic conventions to "pragmadeviate" onto context-informed communicative elements. There are literal propositions in grammatical sentences whose meanings the hearer cannot decode. In such situations, meaning is decoded through cross-cultural pragmatics.

The potency of extra-linguistic approach to the study of speech act is also evident in sentences that are literal yet have unclear propositions. In such sentences, participants rely on mutual contextual knowledge (about the pattern of speaking which characterize the speech community). This trend justifies the argument by scholars "that linguistic meaning is a property of sentences, and the study of illocutionary act is essentially the study of linguistic meaning ${ }^{10}$.

Austin's theory of illocutionary acts does not answer certain questions on how the relationship between "speech acts" and "propositional acts" operates across diverse socio-cultural backgrounds. Savas (1994:3) contends "that it is a logical possibility that among the various components that presumably conspire in determining what speakers of natural languages mean, the illocutionary component should turn out to be relevant in specifying only what these speakers occasionally mean rather than what they standardly mean".

Language is in a continuous state of flux, and this weakens the relationship between locutionary acts and their external relations. There is need for "a system that would characterize the set of all and only those possible act-kinds that would intuitively be regarded as illocutionary act-kinds, by taking some among them as primitive and by specifying operations by means of which all the others could be derived from those taken as primitive" as opined by Savas (Ibid.).

Austin's classification of illocutionary acts is treated in English, which is an Official Language in certain regions of the world. The study does not adequately accommodate the "ethnography of speaking". We acknowledge that the growth of regional standards of English such as SNE (Standard Nigerian English) within the ambit of World Englishes (WE) is a threat to the study of illocutionary act-kinds; see Ayodabo and Acheoah (2013). For instance, WAEC (West African Examinations Council) accepts grammatical components which negate SBE (Standard British English). When speakers perform illocutionary acts, they take responsibility for the different states-of-affairs which their propositions express. Howbeit, several illocutionary verbs do not have contextual potency since their propositional contents do not have existential referents in the form of norms or socio-cultural experiences of some societies. In A7, we understand Austin's position on the intentional nature of illocutionary acts. Illocutionary acts have intrinsic motivators since the primary reason for performing them is speaker-based. But this paper contends "that the mental states (as they are essentially speakers'-intention based) which speakers express in discourse cannot be isolated from the status-quo at which such mental states are directed in speech situations. But the extra-linguistic environments of illocutionary acts have to be systematically categorized so that the study of the appropriateness of locutionary and illocutionary acts can be more illuminating; in a rather sketchy form therefore, we have classified conventions into ethnic, national and global conventions to show that implicatures or conventional meanings which locutionary acts have in different speech communities and contexts determine their use and interpretations both inter-regionally and intra-regionally. If need be, some utterances are processed in discourse so that decoders will be able to understand their illocutionary contents. Since utterances of natural language can be interpreted beyond their standard meaning, there is need for extensive research on the inferential framework for such interpretations. We evolve Geoimplicature which is sociological and belongs to "farside" pragmatics unlike "near-side" pragmatics, which according to Leech (1983), is "formal grammar". The implication of the concept, Geoimplicature, for any critique of Austin's theory is that illocutionary forces could be region-based irrespective of the linguistic agencies that convey them; in other words, Austin's felicity conditions for 
certain acts may not hold for such acts to be felicitous since the norms of the different regions of the world may determine for example, whether B (Bride) has to be a male before BG (Bridegroom) can be proclaimed as the husband to B by a Priest; the participant-factor would have been incompatible/inappropriate for the act to be felicitous if not that the society in which the act is made upholds gay-marriage.

We observe that A1-A11 do not elucidate non-verbal elements of communication, yet such elements are crucial in the study of illocutionary acts. Therefore, Geoimplicature is also rooted in semiotics. For example, we note that in Nigeria, when an object such as a plastic container is placed on a motor vehicle, the people of the speech community know it is for sale. Our position on A1-A11 is that discourse is not simply a mechanical process as discussants who are non-native speakers of English demonstrate socio-cultural competence in their choice of linguistic and para-linguistic elements of communication. In communicative events in Nigeria, the use of English is germane to topic, audience and contexts which can be linguistic, extra-linguistic, broad, and narrow.

Wierzbicka (1991) observes that norms of societies affect their language use. Commenting also on the functions of language in different speech socio-cultural backgrounds, Leech (Ibid.) opines "that the transfer of the norms of one community into another may well lead to pragmatic failure, and to the judgment that the speaker is in some way being impolite, uncooperative, etc." For more insights on cross-cultural pragmatics, see Brown P. and Levinson S., in Goody (1978:56-311).

We have established the argument that Geoimplicature accounts for some of the weaknesses of Austin's speech act theory. We deem it expedient at this juncture to explain Geoimplicature further by discussing some samples of sentences gathered from Nigerian speakers of English at different speech domains. We treat them as (d)-(h) below with relative brevity and precision to show that regional forms of English usage in speech communities where English is alien are sometimes violations from the forms that are intelligible to English native speakers. Our purpose here is not an elaborate analysis that necessitates the usual pragmatic-analyst approach to textual analysis. We merely attempt to highlight extra-linguistic elements in language use from regional perspective via in-text discourse as we analyze the corpora below:

d) Mr. Okon is a Dealer unlike Mr. Adebayo who sells building materials;

(e) V-boot is not an expensive car;

(f) Close-up is good Macleans;

(g) Beware of 419;

(h) We shall buy food from mama-put instead of buying from a restaurant.

In terms of speech act type, (d) is: "Assertive", "Informative", Ascriptive. Mutual contextual knowledge between the encoder and decoder informs and facilitates the interpretation of the speech acts in terms of locutionary, illocutionary and perlocutionary acts. When the encoder of "Dealer" uttered the expression, there was uptake (see A10). In Nigeria, many participants of discourse understand that a "Dealer" is a person who sells motor vehicles, rather than being a business man or a trader. This is a regional meaning as the word "Dealer" is not used denotatively, but connotatively (contextually). Speech acts performed in (e) includes: Assertive, Informative, Ascriptive. The expression "V-boot" presupposes that the referent has a boot that is $\mathrm{v}$-shaped. We infer this from world knowledge. However, through shared knowledge, Nigerians understand "V-boot" as a particular brand of car that is quite known to them, irrespective of the fact that there are diverse kinds of cars with v-shaped boots. It is the Nigerian society that informs names given to different products including vehicles. If for example, there were no traditional title known as "Oba" in Nigeria, there would not have been a car christened "Oba nkio" by Ngerians from the Western part of the country. The expression is the nick name for a particular brand of Mazda saloon car. Since several other vehicles have v-shaped boots, one wonders why the encoder expects his interlocutor to understand the meaning of the utterance. The manufacturers of various vehicles do not have to know that such vehicles have had their factory names changed in other regions of the world. This study observes that even within Nigeria, a particular vehicle has different nick-names in different parts of the country. In other words, "Honda Allah" in Southern Nigeria may have another name in Eastern Nigeria. In the context of this study therefore, the encoder of "V-boot" has employed the pragmatics, not the norms, of English speaking.

It is clear that (f) is both an Assertive and an Ascriptive. The expression, "Macleans", exemplifies cross-cultural pragmatic component since it has a region-based meaning. The encoder uses it as a hyponym for: "Close-up", "Aquafresh" or "Dabur", which are various types of toothpastes. It is pragmatically justifiable (although it is wrong in terms of the norms of English) to say that all brands of toothpaste are "Macleans". The pragmatic principle (pragmatics is principle-governed) behind the usage is that Macleans has clear-cut dominance over other toothpastes; it has more patronage and regard in Nigeria, despite the fact that other brands of toothpastes may be preferred by some Nigerians. We propose to call the dominance of certain products over others "Neutrism" in subsequent studies.

Text (g) is both an Advisory and Warning. Through mutual contextual beliefs, people in the speech community (Nigerians in Nigeria or those who though are not in Nigeria, epitomize the Nigerian dialectics and existential experience) understand " 419 ", and also communicate effectively, using the expression. Nigerians use the utterance "Beware of 419" as inscriptions on vacant houses to scare fraudsters who sell houses that they lay false claim to. In using the expression to perform different speech acts, such Nigerians have communicated effectively, despite that they have regionalized the cardinal beyond the understanding of people from other regions of the world. In Nigeria, if an 
encoder tells his decoder, "Beware of four nineteen" instead of saying, "Beware of four-one-nine" there will be distortion of meaning.

Text (h) is an Assertive. The encoder of "mama-put" employs the shared knowledge he has with his decoder, on what the expression depicts; hence, there was no communication breakdown. The encoder presupposes that his decoder is aware that "mama-put" is antonymous to "restaurant". The expression "mama-put" means "a less standard place for buying and/or eating food". The participants view such a place as being less than the standard of a restaurant, despite the fact that like other restaurants, it might be a room; some "mama-put" spots in Nigeria are mere shades, rather than being rooms for outdoor-meals. We observe also, that the reasons why such spots were given such names included one or all of the following:

-The sellers therein sell very cheap food;

-The places are not good-looking;

- Utensils or cutlery used for serving meals at such spots are unsophisticated.

Since speakers use deviant communicative strategies, as we see in the different linguistic stretches examined above, how can we say they execute discourse procedures completely and correctly as Austin advocates for in A5? Are context-informed grammatical or semantic incorrectness not part of the goals of pragmatics? If speakers cannot flout the rules of language, can we indeed claim that pragmatics emerged as a reaction against the purely-formalist approach to the use of language?

We note that among the locutionary acts or performative verbs, some are more appropriate in certain contexts. Consider:

(i) The shirt was robbed;

(j) The bank was robbed;

(k) The shirt was stolen.

When the verb "robbed" is strewn with the noun "shirt" (in a sentence), the expected sense is not achieved. But when it is paraded with the noun "bank", that sense is achieved. However, a speaker who says, "My shirt was robbed," conveys certain meanings to his decoder. Using speech act verbs contextually depends on the encoder's diction and pragmatic prowess (communicative competence). We do not view the use of sub-standard English by the pragmatic Nigerian literary writer or speaker as linguistic incompetence. We align with the idea that linguistic knowledge has restriction. Alston cited in Savas (Ibid.) cites "that in most cases, Knowledge of the language is not sufficient for grasping what is being said". Put in other words, mastery of the linguistic conventions for the use of illocutionary verbs is not enough for the decoding of what is said in varied contexts. Some sentences have more than one meaning in which case, the decoder relies on contextual nuances to decode them. Let us examine (1)-(n):

(1) We can fish;

(m) I met your wife;

(n) Your wife is having an affair.

(l) can be interpreted in two ways: "we store fish"; and "we are able to fish". In (m), the speaker may mean something other than "mere seeing the wife of another person". Based on contextual clues, the sentence may mean "committing adultery with the so-called wife". Since the distinction between literal and non-literal meaning is not clear-cut, some scholars prefer to talk about a continuum rather than a two-side distinction. We are aware that (n) is used by Thermocool Refrigerator Company as an advertising illocutionary strategy on sign-boards; in which case, the sentence is used as a linguistic accompaniment to the picture of a woman standing beside the product (a fridge). The linguistic and paralinguistic elements put together, interprets (n) as "Your wife is so much in love with the product". We contend that contextual provisions rather than linguistic conventions effectively reveal language use as a thing of credit ${ }^{11}$.We observe that Context-discourse is synonymous with discourse on deep structure semantic primes for linguistic items. In certain contexts therefore, the sentence, "I am a bachelor" can be used by an encoder even though he is not yet married. Similarly, the sentence, "I am not a bachelor" entails "I am not married (among other things that have to do with contextual nuances). Our argument here is similar to that of Hidden Indexicalists who argue that unarticulated elements in an utterance exists at the deep structure level (logical form or semantic representations) and should therefore not be seen as unarticulated by the pragmatic analyst. Indexical expressions are expressions that index time (verbs and adverbs), referents (pronouns) and mood. They have been called "deictic" or "token reflexive expressions" or "egocentric particulars". We maintain that Austin's discussion of speech acts as they apply to institutions is not encompassing. On the contrary, Geoimplicatures capture the extensive and potent use of illocutionary acts in multifacetted domains including religious and commercial domains. Illocutionary forces (speech acts) are intentionally directed towards advertisers' communicative intentions. In commercial adverts, language is mainly a persuasive instrument; in their choice of words, advertisers rely on the mutual knowledge they have with their audience. Presuppositions are potent in commercial sign-board adverts. A pragmatic analysis of language-use in advertisement is an investigation of how language functions in communication between the advertiser and his audience. Simply put, advertisers target their illocutionary contents at society, using social realities (Geoimplicatures).

Socio-cultural attitudes are attached to the choices participants make in expressing the different communicative functions of sentences of natural language; a Nigerian will tell you, "I am coming" to mean "I am going but will be 
back soon". Similarly, when a Nigerian (even an educated Nigerian) is asked, "You are not a Ghanaian?" he/she answers "Yes" to mean "No" (instead of "No"). This kind of situation creates much distortion in the classification of speech acts or illocutionary acts in Austin's frame. But we hold that the crisis point is that Austin's socio-cultural background is germane to his theoretical position whereas the Nigerian speakers of English, just like other non-native speakers of English embody social dialectics which do not reconcile with "Austinian" postulations. Consider:

(o) Can I?

(p) The book, please?

(q) Can you lend me the book?

In o-q, the verb "request" is absent, yet the illocutionary act is understood. Through paraphrases, the claim that some illocutionary acts are communicatively significant whereas others are not can be dislodged. Nigerian speakers dominantly use (q) to make request. The use of (o)-(q) depends on context (extra-linguistics), linguistic and communicative competence of participants of discourse.

According to Austin, for an act of promise made in good faith, the intention of the encoder (that is, whether the encoder is sincere or not), is a prerequisite. But we note that when speech act verbs are used with extra-linguistic calculations, encoders deviate from their conventional use to context-driven illocutionary contents, in which case felicity conditions are inconsequential. For example, "sincerity" may not be relevant in a sentence where an act of promise is used as a Disputative (a speech act type in Bach and Harnish's theory). The exchange below illustrates our claim:

Buyer: What is the last price?

Seller: Five hundred naira.

Buyer: By this time next month, I shall pay three naira for everything. I promise you!

Seller: How?

In the above exchange, Buyer's last utterance, "By this time tomorrow ... promise you" is a Disputative. We may infer the context that informs Buyer's illocutionary act; there might have been the rumour that the government has just taken an action which was about to bring down the price of the commodity. This sudden situation is an Emergent Context. In an Emergent Context, both the encoder and decoder do not anticipate what is emergent. The context is a constituent of the Pragmasociolinguistic Context in Adegbija (1982). If a student disobeys his Lecturer's directive due to an Emergent Context, the perlocutionary effect of the student's action on this Lecturer (after the lecturer had known that the student's reason for disobeying his directive is reasonable) cannot be "disgrace" or "annoyance". In the exchange above, Seller does not understand Buyer's utterance. Put in other words, Seller is unable to locate Buyer's intention. Austin's use of the notion, "speakers' intention" as in A8 is problematic as there are illocutionary acts in which speakers' intentions are not determinable. There are utterances that the hearer cannot respond to, because the intention of the speaker is either doubtful or not known. For instance, in a communicative event, if a speaker utters the sentence above in which the act of promise is used suspiciously by Buyer, the hearer will not be able to locate the speaker's intention unless both have shared knowledge on the illocutionary content.

Austin's theory does not pay much attention to figurative language despite the fact that figurative language is a component of human communication. The theory of indirect speech act can be clearly explained if the use of figurative language in the articulation of illocutionary acts is investigated beyond Austin's theoretical framework which is indeed a good foundation for such investigation. Consider:

(r) There are no dogs in this house so it is open to all;

(s) This is a friendly graveyard therefore, you can urinate here.

Through the agency of "world knowledge", the hearer infers that (r) and (s) are evil-intended, but the hearer may not be right. Nevertheless, it is the duty of the speaker to convince the hearer that the utterances are not evil-intended. At times, communicative acts (verbal and non-verbal elements have to be processed by the encoder so that the inferential process can be facilitated. We have been trying to establish the fact that unlike Bach and Harnish's theory, Austin's theory deemphasized the potent roles which shared knowledge plays in discourse. Without shared knowledge, perlocutionary acts and linguistic conventions which Austin elucidates become problematic. If for example, I decide to persuade Tar by pouring liquid into a glass cup knowing that Tar is very thirsty, my action will not yield expected perlocutionay act unless Tar knows that the liquid is not kerosene. Besides (i) - (k) above, there are other illuminating examples of speech act verbs used connotatively and later processed by the encoder. This point is obvious in the exchange below:

Student A: Why are you laughing?

Student B: I stole my book which was on the teacher's table.

Student A: Since it is yours, why did you say you stole it?

Student B: The teacher seized it from me and I took it without his knowledge and approval.

Adegbija (Ibid.) cites that there are different layers of meaning for the decoding of utterances. The contextual or deviant use of speech act verbs remains true of human communication. Geoimplicatures inform "Pragmadeviants". We coin the term "Pragmadeviant", from the words "pragmatics" and "deviant" to refer to deviant communicative elements used by encoders, with their communicative goals in mind. Using the expression "Hi" to warn a little boy (Cf. Adegbija 1982, 
Unpublished Ph.D Dissertation, Indiana University, Bloomington), is an example of "Pragmadeviant". Commenting on presupposition, Levinson (1983) submits "that the ordinary notion of presupposition should be used to describe any kind of background assumption...theory, expression or utterance makes sense or is rational". It is the background assumption that a father has about how his little baby will interpret the utterance "Hi" in a particular context that informs the usage.

Still on the participant-factor for speech act performance as postulated by Austin, we ponder on the two terms "legitimacy" and "authority" and how they apply to Austin's submission "that a participant performing a directive speech act should be in a position to do so if the act is to be felicitous". We examine the two terms to ascertain whether or not they have the same meaning. It is illegitimate for a Priest to pronounce a man and a woman as husband and wife without their consent, but this Priest has the authority by virtue of his position. By authority, a policeman can enforce the law, but should not take bribe from motorists since such a practice is illegitimate (it is against the law). Similarly, a policeman who has the authority to regulate traffic does not have the legitimacy to do so when not assigned officially to the duty-post where he regulates such traffic. We do not understand whether Austin uses the term "authority" to mean "legitimacy" as well. But how do participants of discourse (motorists and pedestrians) know whether or not the policeman has been officially assigned to the duty-post? Therefore, Austin's use of the term authority has to be clarified to capture discourse realities.

\section{Conclusion}

We align with Pratt (1977) who submits "that speech act theory provides a way of talking about utterances not only in terms of their surface grammatical properties but also in terms of the context in which they are made, the intentions, attitudes, and expectations of the participants, the relationships existing between participants...rules and conventions that are understood to be in play when an utterance is made and received". We note that regional participants of discourse are influenced by socio-cultural and situational variables when they select verbal and non-verbal elements of communication. Factors such as world knowledge, mutual contextual beliefs and presuppositions play vital roles in discourse. However, one of the positions of this paper is that Austin's pioneering work, How to Do Things with Words, remains a springboard for every speech act discourse or theory in modern perspectives.

\section{References}

Austin, J. L.(1962). How to Do Things with Words. Cambridge: Harvard University Press.

Ayodabo, J.O. \& Acheoah, J.E. (2013). Nigerian English in a Decolonized State: Prospects and Constraints. Online International Journal of Arts and Humanities, Volume 2, Issue 2, pp. 48-52.

Bloomfeild, L. (1933). Language. New York: Reinehart and Winston.

Bach, K. \& Robert, H. (1976). Linguistic Communication and Speech Acts. Cambridge, Massachusetts: The MIT Press. Brown, P. and Levinson, S. (1978). Universals in Language Usage: Politeness Phenomena. In Goody (Ed.), Questions and Politeness: Strategies in Social Interaction. Cambridge: Cambridge University Press.

Edwards, J. (1985). Language, Society and Identity. London: Basil Blackwells.

Hymes, D. (1962). The Ethnography of Speaking. In Fishman, J.A. (Ed.), Readings in the Sociology of Language. The Hague: Mouton.

Leech, G. (1983). Principles of Pragmatics. London: Longman.

Levinson, S. (1983). Pragmatics. Cambridge: Cambridge University Press.

Pratt, M. (1977). Towards a Speech Act Theory of Literary Discourse. Bloomington: Indiana University Press.

Savas, T. (1994) (ed.). Foundations of Speech Act Theory. London: Routledge.

Wierzbicka, A. (1991). Cross-cultural Pragmatics. New York: Mouten de Gruyter.

\section{Endnotes}

1. See Goody (Ed.) (1978 Pages 56-311) for Brown and Levinson's paper, Universals in Language Usage: Politeness Phenomena.

2. Before Austin's work How to Do Things with Words, language philosophers focused on the declarative functions of sentences.

3. This tripartite classification shows the relationship that communication elements have with their encoders and decoders in terms of selection and functions.

4. For example, it makes a great difference whether an act of promise is "performed" or "attempted". Perlocutionary sequels are often tied to acts performed.

5. See Bloomfeild, L. (1933) for more insights on the Behavioural Theory of Meaning.

6. The Advocate needs sound mastery of the etiquette of the court in which he pleads his client's case. This pre-knowledge helps him to decide on appropriate ways of addressing, the court, his clients and his witnesses.

7. Apart from interpreting the utterance literally, the decoder may agitate if the encoder says "My wife could not go to church because she was sick."

8. German speakers are said to be very polite in the expression of requests.

9. Encoders often have ideas that inform a given discourse in which they are engaged.

10. The fact "that what a speaker means in uttering a sentence can be arrived at by probing the illocutionary act performed", negates the claim "that the study of illocutionary act is the study of linguistic meaning".

11. Contexts superimpose meanings on sentences; the sentence "I am not a Bachelor" does not just mean "I am married". It may also mean, based on contextual consideration, Can you marry me?" 